\title{
MODES OF TRANSMISSION OF HANSEN'S \\ DISEASE (LEPROSY)
}

B. MoISER

"Hansen's disease" should replace the old term "Leprosy," and the word "leper" should be aboiished completely, and the word "patient" substituted. I think that we are all agreed upon this, so that it cannot be stated too frequently, and that is my excuse for beginning this article in this vein. It will require a long time and much perseverance to put this desideratum into effect, so no opportunity should be missed.

Hansen's disease is generally believed to be spread by contact 
and/or infection, not just occasional, casual contact, but longcontinued, close, intimate contact. I believe this view to be wholly erroneous, and cannot accept it at all after sixteen years full time work at Ngomahuru Hospital, Southern Rhodesia.

Hansen's disease is undoubtedly a house and family disease (by the latter, I do not mean that it is hereditary, for this it certainly is not). Of this, there is ample evidence here. In one case, we have 63 many as six members of a native family-mother, three sons and two daughters-and several cases occur of smaller numbers.

Every patient admitted to Ngomahuru is questioned at great length as to personal and family history, and of more than two thousand cases $60.9 \%$ can give no history of the disease in the family or of any contact with another case, and I decline to believe that it is possible for any native to live with and remain ignorant of the presence of the disease in another, for any length of time.

How is infection to be accounted for in the $60.9 \%$ of cases? Surely, there must be some other form of infection than the human being. Is it possible that there is an intermediate host, or a carrier, as in so many other diseases?

At this hospital, the cockroach was singled out for investigation, mainly because it is cosmopolitan, as is the disease, but also becalise other workers have paid attention to various other possible vectors. Research has been going on here for the last five or six years into cockroaches, not as a full-time occujation but as jart of the general work of the hospital. A Nyasaland African Hospital Orderly, Reuben Zachariah, to whom I owe much for his perseverance, enthusiasm, and trustworthy observation, was taught to us? the microscope (Leitz binocular and Crouch monocular), and he has done most of the donkey-work, collecting roaches, feeding them, making slides and examining them, etc. Without his help, I. could not jossibly have done the work, as I am the only doctor in the place.

There are about one thousand species of cockroach, but only two are common in Southern Rhodesia-Blatel'a yermanica and Oxyhaloa Murrayi (identified in England), the former being the more common. Many hundreds have been examined, both from the hospital area $(8,400$ acres $)$, and from kraals at some distance from the hosjital, and $69 \%$ of all examined show small acid-fast "oval bodlies," ranging from the size of a red blood corpuscle, to that of a small bacillus, such as Hansen's. Most of the oval bodies are opaque and stain very deeply with carbol-fuchsin, but uccasionally a rujtured one is found, the contents being either granular or hacillary and indistinguishable from Hansen's bacillus.

Again, some oval bodies have acid-fast facilli attached to the 
surface, either parallel to the surface or grouped at any angle to it. They have the appearance of Hansen's bacilli. The oval bodies often occur in groups. These phenomena are all very suggestive of some connection with Hansen's disease, but so far there is no definite proof of this.

Oval bodies have not been found here to occur in bed bugs, ticks or flies. They have been observed occasionally in smears made from patients, but I am inclined to think that their appearance herc is accidental, for a photographic dish is used for staining, four slides at a time.

Cockroaches have been fed on mealic meal to which has been added material taken from ulcerating nodules, which material has been proved to contain numerous bacilli of Hansen, and these bacilli have been found in large numbers in the gut of the cockroach, and in the dried faeces. They are sometimes in such large numbers as to suggest multiplication in the gut of the cockroach. The bacilli have been found to remain unchanged in the dried roach's droppings for 169 days (when the contents of the tube were exhausted, so that the period is probably longer than that).

Now, is it not possible that the dried (lroppings of cockroaches are a source of infection, and that this may explain why the disease is a house and family one? Could mfection follow mere rubbing of the droppings on the skin, or follow ingestion in food? It would seem that both are possible. To my mind, this suggested mode of infection is much more plausible and likely than the long, close, intimate contact theory.

rockroaches bite savagely at nigint, leaving on the African's dark skin a white, almost circular scar, of ten much larger than a pin's head. These white scars have been found to contain the bacilli of Hansen, so that it seems almost certain that cockroaches can convey the bacillus from man to man directly. Some of the patients from whom smears were taken from the white scars were early neurals, which were negative in the ears and nose. We have not yet succeeded in making cockroaches bite in the daytime. A sleeve of khaki material was made and applied to the arm of an early neural, with several roaches inserted, but they could not be induced to bite. What we have yet to do is to find Hansen's bacillus in a bite which has actually been observed. A wire gauze cage occupied by a patient and positive roaches at night should supply the informatior.

The skin of an early negative neural case was scarified, and inoculated with positive powdered roach faeces, the scar was found to contain Hansen's bacilli, on the next day, but was negative on the eighth day, when, however, one doubtful "oval body" with bipolar staining was observed. This was in December, 1944, 
and now, at the end of June, 194.5, the inoculation scar has faded, and the patient shows no additional signs and symptoms.

In another experiment, the lried facces of cockroaches left in water for une hour and a half showed no oval bodics, but large number of Hansen's bacilli (query). Had the oval bodies dissolved in the water and set free the Hansen's bacilli (query)?

On 23rd March. 1945 several roaches were caught in Reuben's own house which is within the Hospital grounds, but at least 400 yards from the nearest paticnt's hut, and in one of them bacilli indistinguishable from Hansen's bacillus were found, the first time that they had been found in an unfed roach. This observation was repeated on 19th $A_{1}$ ril, 1945, in the case of one roach caught in "Dem Ciood's" hut, about seven miles from here, where no case of Hansen's discase has ever occurred to our knowledge. The bacilli were numerous, and occurred both in groups and singly.

On 9th June, 1945, of nine BHatellac caughi in the house of a European paticnt, one was found to contain Hausen's bacilli. It had possibly ferl on the patient. Of 230 roaches, caught in various native patients' huts and not fed specially on leprous material, 5.5 were found positive for Hansen's bacilli. Three out of four scars of roach bites or the arm of a young native girl in the "norlular" village of the Hospital werc positive for Hansen's bacilli.

()f six cockroaches fed once with infected material, and which were kejt in separate botties, the faeces being removed laily, all faeces had become negative to Hansen's bacillus on the eighteenth day. In another batch of nine roaches, the facces had become negative on the thirteenth day, and in another lot on the inineteenth day, and in yet another batch on the ninth day. So that. Hansen's bacilli do not appear to last long within the roach (average in these experiments 143 days), though they romain unchanged in dried (lroppings for a very minch longer time.

I am informed that cockroaches are, according to the Fossil Recorls, amıng the most ancient of insects; in the carboniferous period they were by far the most dominant group. Leprosy also is ancient, though in some cases the disease referred to in early records may have been some other disease.

\section{Conclusion}

I think these investigations give some reason to doubt an exclusive contagion and infection theory of the transmission of Hansen's disease from man to man, and give hope that further investigation of cockroaches may produce evidence that the disease is occasionally transmitted by the bite of the roach, and possibly by its dried faces coming into contact with the skin or being ingested with food. 